\title{
The Policy Analysis Matrix (PAM): Comparative Advantage of China's Wheat Crop Production 2017
}

\author{
Ammar Saad ${ }^{1}$, Ruitao Zhang ${ }^{1} \&$ Ying Xia ${ }^{1}$ \\ ${ }^{1}$ Chinese Academy of Agriculture Science, Beijing, China \\ Correspondence: Ying Xia, Chinese Academy of Agricultural Sciences, Beijing, China. E-mail: \\ xiaying@caas.cn
}

Received: August 7, 2019

Accepted: September 11, 2019 Online Published: October 15, 2019

doi:10.5539/jas.v11n17p150

URL: https://doi.org/10.5539/jas.v11n17p150

This research is financed by "Basic Business Expenses of the Chinese Academy of Agricultural Sciences: Research on Agricultural Quality and Green Development" and "The Agricultural Science and Technology Innovation Program (ASTIP-IAED-2019-03)".

\begin{abstract}
As the third-largest crop in China, wheat production plays an essential role in China's agricultural production, food processing and consumption structure. Besides, China is the world's largest wheat producer and consumer, where it produces $14.83 \%$ of the world's total wheat production in 2017 . So it is necessary to analyze and evaluate the government policy for wheat production in China using PAM. This research depends on the data has issued by the National Development and Reform Commission/China statistics press 2018 (National farm production cost-benefit survey 2017). The outcomes of this paper showed that the coefficients measures confirm there is government support for wheat production, that indicates, farmers are getting prices higher than global prices by the continuation of the current policy. While there was no comparable advantage has shown for Chinese wheat product in social prices due to the government intervention in the prices of production outputs. Where this policy representation indexes show that the policy for wheat production 2017 supported the farmers on the consumer cost.
\end{abstract}

Keywords: policy analysis matrix, wheat crop production, Chinese provinces

\section{Introduction}

As the third-largest crop in China, wheat plays an essential role in China's agricultural production, food processing and food consumption structure. Also, China is the world's largest wheat producer and consumer, China's wheat production is $14.83 \%$ of the world's total wheat production in 2017 (FAO, 2019). However, due to the continuous experimental and improvement of labor, land, environmental protection, and quality and safety costs, China's agricultural costs have risen rapidly (Hongxing, 2016); At the same time, the expansion of China's wheat trade deficit has weakened China's wheat trade competitiveness (Yijie et al., 2018).

The existing researches have carried out various studies on China's agricultural trade and international competitiveness and have achieved fruitful results. Aizhi (2006) used the Policy Analysis Matrix (PAM) to analyze the global competitiveness of China's wheat for 1998-2004. The results show that the average domestic resource cost (DRC) of wheat is 1, which is mean; it is just at the ideal balance of interests, but from the DRC values of each year shows that most of the years, the wheat production does not have an advantage and should be adjusted. Xiujuan and Yanhing (2015), and Wang Yijie et al. (2018) analyzed the international competitiveness of China's wheat production by using three indicators: global market share, trade competition index and comparative advantage index, and found that compared with the world's major wheat exporters, China's wheat Industrial competitiveness has apparent disadvantages. In addition to rice, China's leading food (wheat, corn, and soybeans) has lost international competitiveness in terms of production and prices. That China's labor-intensive agricultural products have substantial comparative advantages; land-intensive agricultural products have lost comparative advantages (Jikun \& Hengyun, 2000; Chuanmin, Guoqiang, \& Jinlong, 2003).

From the existing literature, the overall agricultural products are the most studied objects, and they focus on the analysis of traditional indicators, such as domestic resource cost method (DRC), dominant comparative advantage (DCA) and constant market share model (CMS). To evaluate the international competitiveness for China's 
agricultural products, was rare to analyze the global competitiveness of wheat from the perspective of various provinces. In recent years, the policy analysis matrix method (PAM) is widely used in agricultural policy analysis, which belongs to a kind of expansion and innovation of the DRC method. This paper uses the policy analysis matrix method to analyze the international competitiveness of wheat in China on the provinces level. The policy analysis matrix method not only quantifies the comprehensive impact of agricultural policy changes on wheat competitiveness and the income level of grain farmers but also provides an in-depth partial analysis of the specific conditions of wheat input and output.

"We must ensure that China is food secure to have control over our food supply" (Jinping, 2007) and "The grain-landing and grain-saving technology strategy" (The Communist Party of China, 2018) are the primary goals of the recent Chinese agricultural policy. As one of the main rations in China, to stabilize wheat production and increase the enthusiasm of grain farmers, China has implemented the minimum protection price policy in 2006, in the principal wheat-producing areas. The core tenet is "guaranteed supply" and "guaranteed income" (Guoqiang, 2016). Therefore, understanding the international competitiveness of China's wheat is of considerable significance to the stable development of China's wheat industry and the implementation of the food security strategy.

\section{Methodology and Materials}

\subsection{Policy Matrix Analysis}

Quantitative analysis was followed through the use of the policy analysis matrix to derive some indicators and criteria from measuring the impact of government price policy on wheat production in Chinese wheat producer provinces in 2017. This study based on the data published by the National Development and Reform Commission/ China statistics presses 2018 (National farm production cost-benefit survey 2017).

The policy analysis matrix is a quantitative mathematical, analytical method and used to analyze comparative advantage by measuring the impact of government intervention policies and market distortions on the vertical commodity system or commodity chains from farm to final consumption and export point.

The policy analysis matrix defined as a mathematical framework that helps divide the commodity system into its essential components, namely, private profitability estimated at special prices( prices in the local market), social profitability calculated at social prices (prices in the world market), and the difference between the two measures of profitability. The policy analysis matrix is specifically designed to analyze market distortions and price policy interventions and their impact on the commodity system. Where, inputs divided into non-tradable inputs that not internationally traded, such as services and land where the demander and the producer must be in the same location (Jenkins \& Harberger, 2011), and tradable inputs that are internationally traded, such as seed, fertilizer, pesticide, etc.

The work of the Agricultural Policy Analysis Matrix involves finding out several important indicators of protection and comparative advantage. Agricultural Policy Analysis Matrix is the product of two cases of accounting, the first case known as profit, which is the difference between revenue and costs, measured either in private or social expressions. The second case measures the effects of distortions policies or market failures such as the difference between private values and social values, as shown in table 1, by the divergence in the agricultural policy analysis matrix. These differences are estimating by private benefits evaluated at the initial distorted levels of outputs and inputs. Thus, the Agricultural Policy Analysis Matrix guides gradual changes instead of wholesale ones (Monke \& Pearson, 1989).

Table 1. Policy analysis matrix

\begin{tabular}{|c|c|c|c|c|}
\hline & \multirow{2}{*}{ Revenue } & \multicolumn{2}{|c|}{ Costs } & \multirow{2}{*}{ Profit } \\
\hline & & Tradable inputs & Non-tradable inputs & \\
\hline Private prices & A & $\mathrm{B}$ & $\mathrm{C}$ & $\mathrm{D}^{1}$ \\
\hline Social prices & $\mathrm{E}$ & $\mathrm{F}$ & $\mathrm{G}$ & $\mathrm{H}^{2}$ \\
\hline Divergences & $\mathrm{I}^{3}$ & $\mathrm{~J}^{4}$ & $\mathrm{~K}^{5}$ & $\mathrm{~L}^{6}$ \\
\hline
\end{tabular}

Note. ${ }^{1}$ : Private profitability $(\mathrm{D})=\mathrm{A}-(\mathrm{B}+\mathrm{C}){ }^{2}$ : Social profitability $(\mathrm{H})=\mathrm{E}-(\mathrm{F}+\mathrm{G}) ;{ }^{3}$ : Output transfer $(\mathrm{I})=\mathrm{A}$ $-\mathrm{E} ;{ }^{4}$ : Input transfer $(\mathrm{J})=\mathrm{B}-\mathrm{F} ;{ }^{5}$ : Factor transfer $(\mathrm{K})=\mathrm{C}-\mathrm{G} ;{ }^{6}$ : Net policy transfer $(\mathrm{L})=\mathrm{D}-\mathrm{H}$.

Source: Based on Monke and Pearson (1989). 
The values in the first row calculate private profitability or financial profitability (D), which is the differences between private revenues $(\mathrm{A})$ and private costs $(\mathrm{B}+\mathrm{C})$ values at actual market prices. Measures $\mathrm{A}, \mathrm{B}, \mathrm{C}$, and D show taxes and transfers, they show the competitive ability of the agricultural system according to available technologies, output values, input costs, and policy transfers.

The second row of policy analysis matrix table provides social profitability $(\mathrm{H})$ measured at social prices, which is the differences between social revenues (E) and social values costs $(F+G)$. Effective results achieved when the economy, along with its private prices for references to social prices. Social profits measure efficiency gains and provide a measure of comparative advantages (Cheng, 1999).

There are three coefficients used for comparisons between policy incentives and agricultural commodities. The nominal protection coefficient NPC is referring to the level of protection of the main product. Moreover, if the NPC is more significant than 1 , the system takes advantage of the protection and if less than one the system is subject to taxes, where NPC is the ratio of the revenue in the private prices (A) compared to the income of the social costs (E). The Effective Protection Coefficient (EPC) is referred to as the overall level of protection, taking into account the impact of policies on the value of tradable products and tradable inputs. Where it is the ratio of value-added in private market prices $(\mathrm{A}-\mathrm{B})$ to value-added in social market costs $(\mathrm{E}-\mathrm{F})$ (Mamza, Salman, \& Adeoye, 2014). Profitability coefficient PC is measure policy reflection on the profitability of the system. If PC greater than 1 , the system benefits from net transfers from the sector, but if it is smaller than 1 , the economy benefits from net transfers from the system, where it is the ratio of the profit in the private prices (D) compared to the advantage of the social prices (H) (Pearson, Gotsch, \& Bahri, 2003).

There are three indicators used for comparisons of the relative efficiency or comparative advantage among to agricultural commodities. The first indicator is the domestic resource cost DRC if the DRC is smaller than 1, the system has a comparative advantage, which means that we use local resources of lower value than global resources. If the DRC is greater than 1 , the system does not have a comparative advantage, and social profitability is negative where it is the ratio of the non-tradable inputs in the social prices $(\mathrm{G})$ compared to value-added in social costs $(\mathrm{E}-\mathrm{F})$.

Another indicator of the system's comparative advantage, it takes into account the full cost of production of the social prices $(F+G)$, which is more appropriate for the relative position of the different systems when they have different cost structure (tradable and non-tradable). Where DRC is biased in favor of the system containing on a larger scale of tradable inputs, but the Social costs benefit SCB calculated dividing the total costs in the social prices on the revenues of the social prices $(F+G) / E$.

Financial cost-benefit (FCB) is a competitive system index, if FCB is smaller than 1, the system is competitive, and if it is greater than 1 , the system is not competitive and the financial profitability is negative. FCB is the ratio of Non-tradable inputs $(\mathrm{C})$ to value-added in private prices $(\mathrm{A}-\mathrm{B})$.

Two indicators used to measure the policy reflection index/Market distortions change of total system revenues. Producers subsidy ratio (PSR) is policy reflection index/market distortions change of the system's total revenue at social prices, which is the size of the difference from the reference situation at social prices to the current status at local market prices. PSR measured by divided Net policy transfer $(\mathrm{L})$ on revenue in social prices (E).

The second indicator is product subsidy equivalent (PSE) is defined as the policy reflection index/market distortions to increase or decrease the total revenue of the system at local market prices. Where if PSE is positive indicate the policy subsidizes the producers and if it is negative indicates the policy support the consumers. It calculated by divided Net policy transfer (L) on revenue in private prices (A) (Adeoye \& Omobowale, 2013).

\subsection{Data Collection and Calculations}

The assessment of the elements of the policy analysis matrix in the USD needs to know the exchange rate of the Chinese currency against the USD. Because of PAM data from the revenues and costs are valued at local prices, which contain distortions and market failures, and must correct according to world prices.

Social assessment and efficiency analysis by commodity regulations based on international prices, which denominated in foreign currencies. Therefore, it is necessary to know the exchange rate, which is required to estimate global costs.

The exchange rate was adopted in this study, 6.7 Chinese Yuan against the 1 USD, according to the bulletin of the Bank of China 2017. 
The prices of the Policy matrix analysis have been calculated based on the data published by the National Development and Reform Commission/ China statistics press 2018 (National farm production cost-benefit survey 2017).

The data of current situations (production, yield, domestic consumption, and import) have collected from the official website of the Food and Agriculture Organization of the United Nations (FAO) (2019).

\section{Result and Discussion}

\subsection{Policy Matrix Analysis}

After calculating the production inputs costs and revenues at private and social prices, we can build components estimates of policy analysis matrix by filling the rows and columns of the sample.

The matrix built based on the production of one hectare and provinces level, and the average of the sample USD/ha of the wheat production, Table 2 shows the results of the policy analysis matrix for the production of wheat in China 2017 on provinces level.

The results of the matrix indicate that the wheat crop in the provinces (Hebei, Neimenggu, Heilongjiang, Jiangsu, Anhui, Henan, Xinjiang and the average of the total sample) are profits earned to the producers in the private prices, where $\mathrm{D}$ values were positive. As for the other provinces, the results of the matrix indicate that the wheat crop is non-profits earned and non-compliance with capital expenditure for wheat production in the private prices, where $\mathrm{D}$ values were negative.

While the wheat crop in the social profitability $(\mathrm{H})$ in all of the provinces in this study were negative, this indicates the waste use of non-tradable inputs (local resources), which requires to encourage for efficient use of resources by introducing modern technologies. Namely, the system of wheat production in China is not able to survive without assistance from the government; this indicates the inefficiently use of non-tradable inputs (local resources). So it is required to increase productivity or reduced production costs through the use of resources efficiently by introducing modern technologies patterns and redistributing resources efficiently.

The price policy does not encourage to the efficient use of local resources, while the results also show that the divergences revenues (I) were positive in all the provinces matrices of the study, which were the results of the difference between the private prices revenues $(\mathrm{A})$ and the social prices revenues $(\mathrm{E})$. That means the private revenues are higher than the social revenues of all the matrices, which indicates the high government intervention for wheat production 2017, resulted from the government intervention through making the price of the wheat production in a local price higher than global price, and market failures.

The divergences of tradable inputs $(\mathrm{J})$ were zero in the results of the matrix for all the provinces, which means that the tradable inputs in social prices are equivalent to tradable inputs in private prices, which indicates that there is no any subsidy or tax on tradable inputs. As well as the market failures, has shown from divergences of non-tradable inputs $(\mathrm{K})$ in all provinces were zero, which also indicates that there is no subsidy or tax on non-tradable inputs.

The positive value of the net effect (L) resulted in policy matrix analyses Table 2 for every province of this study indicates that the wheat production in 2017 in China is more profitable for producers with market distortions than the profitability without market distortions. Government intervention policies in the wheat commodity system reflected on the output prices, which is for the benefit of domestic producers for short-term (Mohammed, 2015). 
Table 2. The results of the policy analysis matrix for the production of one hectare of wheat in China 2017

\begin{tabular}{|c|c|c|c|c|c|}
\hline \multirow{2}{*}{ Provinces } & & \multirow{2}{*}{ Revenue } & \multicolumn{2}{|c|}{ Costs } & \multirow{2}{*}{ Profit } \\
\hline & & & Tradable inputs & Non-tradable inputs & \\
\hline \multirow{3}{*}{ HEBEI } & Private prices & 2645.55 & 1089.72 & 1315.81 & 240.02 \\
\hline & Social prices & 1955.92 & 1089.72 & 1315.81 & -449.61 \\
\hline & Divergences & 689.63 & 0.00 & 0.00 & 689.63 \\
\hline \multirow{3}{*}{ SHANXI 1} & Private prices & 2195.98 & 1145.17 & 1104.23 & -53.43 \\
\hline & Social prices & 1611.46 & 1145.17 & 1104.23 & -637.94 \\
\hline & Divergences & 584.51 & 0.00 & 0.00 & 584.51 \\
\hline \multirow{3}{*}{ NEIMENGGU } & Private prices & 2602.32 & 1029.02 & 1499.16 & 74.14 \\
\hline & Social prices & 1580.48 & 1029.02 & 1499.16 & -947.70 \\
\hline & Divergences & 1021.84 & 0.00 & 0.00 & 1021.84 \\
\hline \multirow{3}{*}{ HEILONGJIANG } & Private prices & 1390.97 & 694.95 & 676.46 & 19.56 \\
\hline & Social prices & 1299.64 & 694.95 & 676.46 & -71.77 \\
\hline & Divergences & 91.33 & 0.00 & 0.00 & 91.33 \\
\hline \multirow{3}{*}{ JIANGSU } & Private prices & 2230.75 & 1032.58 & 1086.52 & 111.64 \\
\hline & Social prices & 1768.06 & 1032.58 & 1086.52 & -351.05 \\
\hline & Divergences & 462.69 & 0.00 & 0.00 & 462.69 \\
\hline \multirow{3}{*}{ ANHUI } & Private prices & 2298.83 & 933.94 & 997.00 & 367.89 \\
\hline & Social prices & 1848.89 & 933.94 & 997.00 & -82.04 \\
\hline & Divergences & 449.93 & 0.00 & 0.00 & 449.93 \\
\hline \multirow{3}{*}{ HENAN } & Private prices & 2529.65 & 1037.42 & 1204.78 & 287.45 \\
\hline & Social prices & 1887.97 & 1037.42 & 1204.78 & -354.23 \\
\hline & Divergences & 641.68 & 0.00 & 0.00 & 641.68 \\
\hline \multirow{3}{*}{ SHANDONG } & Private prices & 2404.21 & 1014.07 & 1416.16 & -26.02 \\
\hline & Social prices & 1966.83 & 1014.07 & 1416.16 & -463.41 \\
\hline & Divergences & 437.38 & 0.00 & 0.00 & 437.38 \\
\hline \multirow{3}{*}{ HUBEI } & Private prices & 1562.91 & 779.26 & 804.48 & -20.83 \\
\hline & Social prices & 1332.44 & 779.26 & 804.48 & -251.31 \\
\hline & Divergences & 230.48 & 0.00 & 0.00 & 230.48 \\
\hline \multirow{3}{*}{ SICHUAN } & Private prices & 1287.07 & 584.24 & 1748.25 & -1045.42 \\
\hline & Social prices & 991.69 & 584.24 & 1748.25 & -1340.79 \\
\hline & Divergences & 295.37 & 0.00 & 0.00 & 295.37 \\
\hline \multirow{3}{*}{ YUNNAN } & Private prices & 1298.64 & 500.57 & 1730.88 & -932.81 \\
\hline & Social prices & 973.07 & 500.57 & 1730.88 & -1258.39 \\
\hline & Divergences & 325.58 & 0.00 & 0.00 & 325.58 \\
\hline \multirow{3}{*}{ SHANXI 2} & Private prices & 2064.45 & 931.54 & 1421.32 & -288.42 \\
\hline & Social prices & 1704.57 & 931.54 & 1421.32 & -648.30 \\
\hline & Divergences & 359.88 & 0.00 & 0.00 & 359.88 \\
\hline \multirow{3}{*}{ GANSU } & Private prices & 1528.43 & 940.84 & 1591.48 & -1003.89 \\
\hline & Social prices & 1189.60 & 940.84 & 1591.48 & -1342.72 \\
\hline & Divergences & 338.84 & 0.00 & 0.00 & 338.84 \\
\hline \multirow{3}{*}{ NINGXIA } & Private prices & 2027.04 & 1112.73 & 1592.68 & -678.37 \\
\hline & Social prices & 1419.55 & 1112.73 & 1592.68 & -1285.86 \\
\hline & Divergences & 607.49 & 0.00 & 0.00 & 607.49 \\
\hline \multirow{3}{*}{ XINJIANG } & Private prices & 2676.83 & 1156.95 & 1153.23 & 366.65 \\
\hline & Social prices & 1699.57 & 1156.95 & 1153.23 & -610.61 \\
\hline & Divergences & 977.26 & 0.00 & 0.00 & 977.26 \\
\hline \multirow{3}{*}{ AVARAGE } & Private prices & 2269.57 & 982.05 & 1273.86 & 13.65 \\
\hline & Social prices & 1748.66 & 982.05 & 1273.86 & -507.26 \\
\hline & Divergences & 520.91 & 0.00 & 0.00 & 520.91 \\
\hline
\end{tabular}




\subsection{Analyze Results}

Based on the estimates of the policy analysis matrix for wheat production in China 2017, shown in Table 2 for the matrix of provinces and the average of the total sample. We can calculate the protection coefficients and comparative advantage measures, which are economic indicators that can measure the impact of government intervention on input and output prices and market failures, as well as the efficiency of the use of resources.

\subsubsection{The Coefficients Measure}

It noted that the Nominal Protection Coefficient NPC of production was more significant than 1 for every province and the average of the total sample, as shown in Table 3. It means that the price protected for wheat to be higher than the world market price, which indicates that there is government support for wheat output and that means, producers, get prices higher than global prices with the existence of this policy. Where the local price for wheat production was $130 \%$ of the global market price for the average of the total sample. It called positive protection for producers. Conversely, consumers face negative protection, and they have to pay higher prices for obtaining the wheat has produced by the existing government policy.

While the Effective Protection Coefficient (EPC) for all of the study sample was positive and greater than 1, as shown in Table 3 (coefficients Indicators). It means that the added value of wheat production at private prices is higher than the value added at social prices, where the added value at private prices is $168 \%$ for value-added at social prices. Indicating positive protection for wheat production in China 2017 resulting from the determinate the wheat price by the government at a price higher than the effect of customs duties on imports wheat. Positive protection for wheat production makes private profits higher than social benefits, which also shows that the wheat market in China is not sufficiently competitive.

The Profitability Coefficient (PC) index values in every province and the total sample was less than 1, that is mean the private profits (D) were always higher than social profits $(\mathrm{H})$. D higher than $\mathrm{H}$ indicates that the wheat production system in China does not benefit from the government subsidy policy to achieve high social profits compared to private profits.

\subsubsection{The Comparative Advantage Measure}

Financial costs benefit FCB values were smaller than 1 for (Hebei, Neimenggu, Heilongjiang, Jiangsu, Anhui, Henan, Xinjiang, and the average of the total sample), as shown in Table 3. Which means the system is competitive in private prices; namely, the system generates private profits. As for the other provinces, the results of the FCB values were more significant than one indicates that the system does not generate profits in private prices.

On the other hand, Domestic resources cost DRC values for every province was more significant than 1, namely the system has no comparative advantage, which means using local resources higher value than global resources.

As well as the social costs benefit SCB, which is the other indicator of the system's comparative advantage, it takes into account the full cost of production of the social prices, confirmed the DRC finding. Where SCB values for all of the sample of the study were negative, which means the system has no comparative advantage and the colossal waste of resources use as shown in Table 3 (Comparative advantage Indicators).

\subsubsection{The Policy Reflection Index/Market Distortions}

The positive values of Product Subsidy Equivalent PSE for every province and total sample means the government policy support producer, namely overall transfer to the producer from consumer. The product subsidy rates PSR values were positive in every province, indicated that there are real support and positive incentives for domestic producers of the wheat crop in China 2017, where average PSR of the whole sample was $30 \%$. The government price determination of the product explains this high incentive price, the average price of $350 \mathrm{USD} /$ ton approximately, and the consequent, rise in wheat prices in local markets. 
Table 3. Indicators of the policy analysis matrix

\begin{tabular}{|c|c|c|c|c|c|c|c|c|}
\hline \multirow[t]{2}{*}{ Provinces } & \multicolumn{3}{|c|}{ Coefficients Indicators } & \multicolumn{3}{|c|}{$\begin{array}{l}\text { Comparative advantage } \\
\text { Indicators }\end{array}$} & \multicolumn{2}{|c|}{$\begin{array}{c}\text { Indicators of policy } \\
\text { reflection index/market } \\
\text { distortions }\end{array}$} \\
\hline & NPC & EPC & $\mathrm{PC}$ & DRC & FCB & SCB & PSE & PSR \\
\hline HEBEI & 1.35 & 1.80 & -0.53 & 1.52 & 0.85 & -5.35 & 0.26 & 0.35 \\
\hline SHANXI 1 & 1.36 & 2.25 & 0.08 & 2.37 & 1.05 & -3.53 & 0.27 & 0.36 \\
\hline NEIMENGGU & 1.65 & 2.85 & -0.08 & 2.72 & 0.95 & -2.67 & 0.39 & 0.65 \\
\hline HEILONGJIANG & 1.07 & 1.15 & -0.27 & 1.12 & 0.97 & -19.11 & 0.07 & 0.07 \\
\hline JIANGSU & 1.26 & 1.63 & -0.32 & 1.48 & 0.91 & -6.04 & 0.21 & 0.26 \\
\hline ANHUI & 1.24 & 1.49 & -4.48 & 1.09 & 0.73 & -23.54 & 0.20 & 0.24 \\
\hline HENAN & 1.34 & 1.75 & -0.81 & 1.42 & 0.81 & -6.33 & 0.25 & 0.34 \\
\hline SHANDONG & 1.22 & 1.46 & 0.06 & 1.49 & 1.02 & -5.24 & 0.18 & 0.22 \\
\hline HUBEI & 1.17 & 1.42 & 0.08 & 1.45 & 1.03 & -6.30 & 0.15 & 0.17 \\
\hline SICHUAN & 1.30 & 1.72 & 0.78 & 4.29 & 2.49 & -1.74 & 0.23 & 0.30 \\
\hline YUNNAN & 1.33 & 1.69 & 0.74 & 3.66 & 2.17 & -1.77 & 0.25 & 0.33 \\
\hline SHANXI 2 & 1.21 & 1.47 & 0.44 & 1.84 & 1.25 & -3.63 & 0.17 & 0.21 \\
\hline GANSU & 1.28 & 2.36 & 0.75 & 6.40 & 2.71 & -1.89 & 0.22 & 0.28 \\
\hline NINGXIA & 1.43 & 2.98 & 0.53 & 5.19 & 1.74 & -2.10 & 0.30 & 0.43 \\
\hline XINJIANG & 1.58 & 2.80 & -0.60 & 2.13 & 0.76 & -3.78 & 0.37 & 0.58 \\
\hline Total Sample & 1.30 & 1.68 & -0.03 & 1.66 & 0.99 & -4.45 & 0.23 & 0.30 \\
\hline
\end{tabular}

\section{Conclusions and Recommendations}

\subsection{Conclusions}

The results of agricultural policy analysis of the wheat crop producer provinces in China 2017 showed that the crop generates private profits in some provinces (Hebei, Neimenggu, Heilongjiang, Jiangsu, Anhui, Henan, Xinjiang and the average of the total sample) only. As for social profits, there is no province achieved social profits where they are producing negative social profits. That means there are misuse and misdistribution of the local resources.

The analysis of product protection indicators shows that the government is subsidizing the production output by the determinate the production at higher prices than world market prices, which explains the rise in private profits compares to social profits.

The indicators of comparative advantage indicated that the comparative advantage does not characterize the wheat crop in China, despite the achievement of some provinces in this study for private profits. That is reflexing the inefficient use of resources in Chinese wheat farms through the government intervention and market distortions of the product that discourages to optimize the use of resources.

\subsection{Recommendations}

Based on the findings of the research, we can come up with some recommendations:

(1) Redistributing resources more efficiently and encourage farmers to make optimum use of resources.

(2) Adoption of modern farming methods such as the adoption of modern irrigation methods to face water scarcity and to increase the productivity of wheat crop production or reduce the production costs.

\section{References}

Adeoye, I., \& Omobowale, O. (2013). Policy Analysis and Competitiveness of Plantain Processing in January 2016.

Aizhi, Y. (2006). Quantitative Analysis of Chinese Agricultural Policy Effect in Recent Years: Based on Policy Analysis Matrix Approach. Chinese Academy of Agricultural Sciences, China.

Cheng, F. (1999). Food self-sufficiency, comparative advantage, and agricultural trade: A policy analysis matrix for Chinese agriculture. Center for Agricultural and Rural Development, Iowa State University.

Chuanmin, S., Guoqiang, C., \& Jinlong, Z. (2003). An Estimation of the International Competitiveness of China's Produces. Management World, 97(01), 103-153. https://doi.org/10.1142/S0219747203000074

FAO (Food and Agriculture Organization of the United Nations). (2019). Retrieved from http://www.fao.org/ 
faostat/zh/\#data/QC

Guoqiang, C. (2016). The Logic and Thinking of China's Grain Price Policy Reform. Issues in Agricultural Economy, 37(0.2), 4-9.

Hongxing, N. (2016). Watch out for the Three Risks Facing China's Agriculture. Nong Chan Pin Shi Chang Zou Kan, 50, 62-63.

Jenkins, G. P., \& Harberger, A. C. (2011). Cost-Benefit Analysis for Investment Decisions (Chapter 11). Cost-Benefit Analysis for Investment Decisions (2011 Manuscript, pp. 1-38).

Jikun, H., \& Hengyun, M. (2000). Price Difference: International Comparison of Prices of Major Agricultural Products in China. Intertrade, 10, 20-24.

Jinping, X. (President of the People's Republic of China). (2007). Secure a Decisive Victory in Building a Moderately Prosperous Society in All Respects and Strive for the Great Success of Socialism with Chinese Characteristics for a New Era. Retrieved from http://language.chinadaily.com.cn/19thcpenationalcongress/ 2017-11/06/content_34188086_2.htm

Mamza, A. O., Salman, K. K., \& Adeoye, I. B. (2014). A Policy Analysis Matrix Approach (Vol. 6, No. 2, pp. 132-147).

Mohammed, N. J. (2015). Measuring of The Comparative Advantage and Competitiveness on Wheat Production in Iraq by Using Policy Analysis Matrix (No. 1025, p. 260).

Monke, E., \& Pearson, S. R. (1989). The Policy Analysis Matrix for Agricultural Development. Cornell University Press, Ithaca and London. https://doi.org/10.1080/03768359008439507

Pearson, S., Gotsch, C., \& Bahri, S. (2003). Applications of the Policy Analysis Matrix in Indonesian Agriculture (p. 368). Retrieved from https://books.google.com.co/books?id=NrLoroQvkRMC\&pg=PA19\&lpg=PA19\& $\mathrm{dq}=$ Applications + of + the + Policy + Analysis + Matrix $+\mathrm{in}+$ Indonesian + Agriculture \&source $=$ bl\&ots=PMuVD6 _FVx\&sig=A91gRlrNW1DK6ny_5mXcEhLZTW8\&hl=es\&sa=X\&ei=nm_iVM7PEITYgwTU3YHIBQ\&v ed $=0$ CEYQ6AEwBA\# $\mathrm{v}=$ onep

The Communist Party of China. (2018). Opinions of the CPC Central Committee and the State Council on Implementing the Rural Revitalization Strategy. Retrieved from http://www.gov.cn/zhengce/2018-02/04/ content_5263807.htm

Xiujuan, G., \& Yanhang, W. (2015). Analysis of International Competitiveness of wheat industry of China. Industrial \& Science Treibune, 14, 11-12.

Yijie, W., Ling, X., Zhiquan, H., \& Xiaoning, A. (2018). Current situation of production, consumption and trade of wheat in China. Chinese Journal of Agricultural Resources and Regional Planning, 39(05), 36-45.

\section{Copyrights}

Copyright for this article is retained by the author(s), with first publication rights granted to the journal.

This is an open-access article distributed under the terms and conditions of the Creative Commons Attribution license (http://creativecommons.org/licenses/by/4.0/). 